\title{
Retention of Cellulose, Xylan and Lignin in Kraft Pulping of Eucalyptus Studied by Multivariate Data Analysis: Influences on Physicochemical and Mechanical Properties of Pulp
}

\author{
Pedro Fardim ${ }^{*, a}$ and Nelson Durán ${ }^{a, b}$ \\ ${ }^{a}$ Instituto de Química, Universidade Estadual de Campinas, CP 6154, 13084-971 Campinas - SP, Brazil \\ ${ }^{b}$ Núcleo de Ciências Ambientais,Universidade de Mogi das Cruzes, 08780-911 Mogi das Cruzes - SP, Brazil
}

\begin{abstract}
Um planejamento fatorial completo foi empregado na investigação dos efeitos das variáveis de polpação kraft de eucalipto nas retenções de carbohidratos e lignina. As influências da retenção desses componentes nas propriedades físico-químicas e mecânicas da polpa foram avaliadas usando o método de Análise de Componentes Principais. O álcali ativo (AA) foi a variável que mais afetou a degradação macromolecular da celulose e as retenções de xilana e lignina. A retenção da celulose não foi afetada. O uso de baixo nível de AA na polpação favoreceu todas as propriedades mecânicas da polpa, porém apresentou efeito negativo na alvura ISO e número kappa. O grau médio de polimerização da celulose apresentou relação com o módulo elástico e com o índice de tração enquanto que a xilana apresentou relação com densidade aparente das folhas. $\mathrm{O}$ índice de rasgo apresentou influência positiva do comprimento médio das fibras e dos ácidos urônicos, que foram preservados na xilana possivelmente devido a combinação de baixo AA, baixa espessura dos cavacos e curto ciclo de polpação. A característica, mais do que o conteúdo de xilana na polpa, foi sugerido como fator relevante ao índice de rasgo.
\end{abstract}

Effects of pulping variables on the retention of carbohydrates and lignin in fast kraft pulping of eucalyptus were investigated using a complete factorial design. Influences of pulp chemical composition on physicochemical and mechanical properties were evaluated using Principal Component Analysis. Active alkali (AA) significantly affected the macromolecular degradation of cellulose and retention of xylan and lignin. Cellulose retention was unaffected. The use of low AA in pulping improved all mechanical properties, but increased the kappa number and reduced ISO brightness. The degree of polymerization of cellulose was related to tensile index and elastic modulus while xylan affected the apparent sheet density. Tear index had a positive influence of fiber length and uronic acid groups, which were preserved in xylan by a combination of low AA, thin wood chips and a short pulping cycle. The characteristics, rather than the content of xylan, were suggested to be relevant to tear index.

Keywords: eucalyptus, alkaline degradation, carbohydrates, lignin, multivariate data analysis

\section{Introduction}

Kraft pulping and its improved versions are widely used in pulp production due to its simplicity compared to other processes, high strength of the pulps and tolerances to variations in the wood species and quality. Chemicals such as $\mathrm{NaOH}$ and $\mathrm{Na}_{2} \mathrm{~S}$ are employed in pulping liquor to separate fibers from wood at high temperatures, leading to different extents of degradation of lignin and carbohydrates. ${ }^{1}$ Hemicelluloses are more susceptible to alkaline hydrolysis than cellulose due to their low degree of polymerization, amorphous state and accessibility to

\footnotetext{
* e-mail: pfardim@abo.fi

Present address: Åbo Akademi University, Porthansgatan 3, FIN20500, Turku/Åbo, Finland.
}

the pulping liquor. The degradation, dissolution, and retention of fiber components during pulping are the main factors affecting the unbleached pulp chemical composition. ${ }^{2}$ In fact, degradation and retention are distinct phenomena. A component can be degraded and not dissolved and thus be retained in the fiber matrix. As a consequence, neither macromolecular nor ultrastructural degradation will be directly related to pulping yield, which is dependent on component retention.

Macromolecular degradation of carbohydrates under alkaline conditions was extensively studied and reaction pathways such as end-wise degradation, termination, and alkaline scission are currently accepted. ${ }^{3}$ Lignin degradation was reported in numerous studies and attributed mainly to nucleophilic attach of low density 
electron positions in the lignin phenyl-propane units. ${ }^{4}$ More recently, it has been proposed that the carbohydrate degradation is homogeneous at the molecular level ${ }^{5}$ and probably affected by physical factors. ${ }^{6}$ The role of morphological factors on the degradation reaction rates during pulping are still unclear and limited due to accessibility and uneven component distribution across the cell wall, and on different wood cells. ${ }^{7}$

Deposition or sorption of hemicelluloses and lignin onto fiber surfaces during pulping also influence the retention and consequently affect the technical parameters of pulp. ${ }^{8}$ Retention of hemicelluloses was improved by a combination of chip width and pulping conditions for softwood ${ }^{9}$, indicating the influence of physical factors. ${ }^{10} \mathrm{It}$ is believed that hemicelluloses retention is promising due to an increase in pulping yield and positive effects on pulp beating and strength properties. ${ }^{11-13}$ Several investigations concerning degradation and dissolution of carbohydrates and lignin in eucalyptus pulping ${ }^{14-16}$ and effects of fiber morphology on pulp properties ${ }^{17-19}$ have been reported. However, effects of pulping variables on component retention and the relationship between lignin, cellulose and individual hemicelluloses present in eucalyptus pulp on physicochemical and strength properties remain unreported.

In this study, the effects of pulping variables on the retention of carbohydrates and lignin were investigated using a complete factorial design. The influences of eucalyptus pulp chemical composition on physicochemical and mechanical properties were investigated using Principal Component Analysis (PCA).

\section{Experimental}

\section{Pulping conditions and characterizations of wood and pulps}

Wood of Eucalyptus grandis trees, eight years old, was used to make chips employing an industrial chipper. Chip fractions in the width range of 2-5 mm and length range of 16-45 mm were selected for kraft pulping using a bar and hole chip classifier. The pulping conditions were defined based on a complete factorial design with four factors and two levels as presented in Table 1. A set of 16 experiments was performed according to a randomized disposition using a 20-liter laboratory reactor equipped with a heating rate controller. A constant wood/liquor ratio of $4: 1, \mathrm{H}$ factor of $400 \pm 20$ and $1000.0 \mathrm{~g}$ of chips (o.d.) was used for all experiments. After pulping the unbleached pulp samples were washed with tap water until the $\mathrm{pH}$ of the filtrate was around 6.8. Pulp yield was determined by screening in a stainless steel vibrating system with a bar aperture of 2.0 $\mathrm{mm}$. The $\mathrm{AA}$ and $\mathrm{S}$ were determined in pulping liquor according to SCAN N2:88 and SCAN N 3:63, respectively.

Table 1. Factors and levels used in pulping experiments

\begin{tabular}{lcc}
\hline Factor & $(-)$ & $(+)$ \\
\hline Temperature $(\mathrm{T}),{ }^{\circ} \mathrm{C}$ & 160 & 170 \\
Heating rate $(\mathrm{V}),{ }^{\circ} \mathrm{C} / \mathrm{min}$ & 1.9 & 3.8 \\
Sulfidity (S), $\%$ & 23.3 & 31.1 \\
Active alkali (AA), $\% \mathrm{NaOH}$ & 15.5 & 23.3 \\
\hline
\end{tabular}

D-glucose, D-xylose, D-mannose, L-arabinose, Dgalactose and L-rhamnose were determined in acidic pulp hydrolyzates using HPLC-PAD. ${ }^{20}$ Uronic acids were determined according to the Scott method. ${ }^{21}$ The polysaccharide composition of pulp samples was calculated according to Janson. ${ }^{22}$ Acid insoluble and soluble lignins were determined according to Effland $^{23}$ and TAPPI UM 250, respectively. Kappa and intrinsic viscosity (IV) were determined according to TAPPI T 236:85 and SCAN C15-16:62, respectively. Degree of polymerization (DP) of cellulose was estimated using IV and the amount of hemicelluloses in the pulp. ${ }^{24,25}$ ISO brightness was measured using a spectrometer DATACOLOR 3300 according to ISO 3688. Zeta potential was estimated by the measurement of electrophoretic mobility in pulp suspensions in deionised water at $0.2 \%$ consistency using the MOBILITY METER MARK II (Paper Chemistry Consulting Laboratories). The conductivity of the suspensions was in the range of $20-25 \mu \mathrm{Scm}^{-1}$ and $\mathrm{pH}$ was in the range of 6.5-7.0. Calibrations were performed using silica particles supplied by the instrument manufacturer. At least 10 measurements were done on each sample. The coefficient of variation (CV) was lower than $7 \%$. The length weighted fiber length was measured using a KAJAANI fiber length analyzer. At least five measurements were performed on each sample with more than 20000 fibers counted in each run. Under these conditions the CVs observed were lower than $3 \%$. Tear, burst and tensile indices were determined according to ISO 5270. Stretch, breaking length and elastic modulus were determined according to ISO 1924/2 and bending resistance according to ISO 2493. All mechanical properties were measured on pulp hand sheets prepared with a Rapid Köthen apparatus using deionised water and properly conditioned at a temperature of $23 \pm 1{ }^{\circ} \mathrm{C}$ and relative humidity of $50 \pm 2 \%$. At least 10 handsheets were analysed for each mechanical property. Only unrefined pulp samples were characterized. The analytical variations were determined by calculation of $\mathrm{CV}$ for each property. Measured CVs ranged up to $8 \%$. 


\section{Multivariate data analysis}

The effects of each variable on cellulose, xylan and lignin retentions and on the content of uronic acids in xylan were estimated using a complete factorial design. A computer program (STATISTICA 4.5) was used for the estimation of the main effects and interactions between two, three and four factors using retention data obtained from chemical analysis and screened pulping yield. The experimental errors for each effect and interaction were estimated using two methods, analysis of variance (ANOVA) and normal plot. ${ }^{26}$ The results obtained by both methods were similar, but only the normal plot is presented here.

Principal component analysis (PCA) is a multivariate data analysis method suitable for describing major trends in a data set and also the relations between samples and between variables. In PCA, a multivariate matrix $\mathbf{X}$ with $m$ rows and $n$ columns, with each sample being a row and each variable being a column, is decomposed as the sum of the outer product of vectors $\mathbf{t}_{\mathrm{i}}$ and $\mathbf{p}_{\mathrm{i}}$ plus a residual matrix $\mathbf{E}$. The $\mathbf{t}_{\mathrm{i}}$ vectors are known as scores and give information on how samples are related to each other. The $\mathbf{p}_{\mathrm{i}}$ vectors are known as loadings and give information on how the variables are related to each other. A detailed description of PCA method can be found in literature. ${ }^{27}$ Two matrices were done to study effects of pulp chemical composition on physicochemical and mechanical properties, respectively. In the first matrix, kappa number, ISO brightness, intrinsic viscosity, zeta potential and the contents of cellulose, xylan, uronic acids, and total lignin were introduced as columns while the samples obtained in the 16 pulping experiments were added as rows, forming a $16 \times 8$ data matrix. In the second matrix aiming at studying mechanical properties, elastic modulus, stretch, fiber length, apparent sheet density, cellulose/hemicellulose ratio, degree of polymerization of cellulose and tensile, tear, burst and bending indices were used in addition to chemical composition data forming a 16 x 14 data matrix. Both matrices were autoscaled, i.e. adjusted to zero mean by subtracting the original mean of each column and then adjusted to unit variance by dividing each column by its standard deviation. The latter operations and PCA were performed using a computer program (MATLAB 6).

\section{Results and Discussion}

\section{Wood chemical composition}

The chemical composition of wood used in pulping experiments is presented in Table 2. The total yield was $96.7 \%$ and the remaining fraction was associated with acetyl groups and possible minor losses due to furfural and methylfurfural formation during acid hydrolysis. Xylan, as indicated by xylose content, was the main hemicellulose component and the lignin level was typical of hardwoods.

Table 2. Chemical composition of extractives-free wood of E. grandis, carbohydrates as anhydro sugars. The content of extractives in ethanol-toluene was $1.2 \%$

\begin{tabular}{lc}
\hline Component & $(\%)$ of dry wood \\
\hline Glucose & 51.1 \\
Xylose & 13.3 \\
Galactose & 0.7 \\
Mannose & 0.4 \\
Rhamnose & 0.2 \\
Arabinose & 0.2 \\
Uronic acids & 4.4 \\
Lignin & 26.2 \\
Ash $\left(575 \pm 25^{\circ} \mathrm{C}\right)$ & 0.2 \\
\hline
\end{tabular}

Screening yield and physicochemical properties of pulps

Table 3 shows the results obtained for screening yield, kappa number, intrinsic viscosity, ISO brightness, and zeta potential. Levels obtained in the laboratory experiments showed higher values for screening yield than those generally reported at the same kappa and viscosity, i.e. around 53\%. ${ }^{14}$

Table 3. Screening yield as $\%$ of original wood, kappa number, intrinsic viscosity (IV) as $\mathrm{cm}^{3} \mathrm{~g}^{-1}$, ISO brightness (BR) as \% ISO, zeta potential (ZP) as $\mathrm{mV}$ measured on laboratory pulps. Pulps obtained in experiments according to a complete factorial experimental design. The combination of factors and levels described in Table 1 is presented as $(\mathrm{T}, \mathrm{V}, \mathrm{S}, \mathrm{AA})$

\begin{tabular}{ccccccc}
\hline Experiment & $(\mathrm{T}, \mathrm{V}, \mathrm{S}, \mathrm{AA})$ & Yield & Kappa & $\mathrm{IV}$ & $\mathrm{BR}$ & $\mathrm{ZP}$ \\
\hline 1 & $(-,-,-,-)$ & 56.7 & 27.8 & 1288 & 30.9 & -91.1 \\
2 & $(+,-,-,-)$ & 61.2 & 28.4 & 1135 & 28.8 & -76.1 \\
3 & $(-,+,-,-)$ & 60.7 & 31.9 & 1073 & 26.0 & -80.2 \\
4 & $(+,+,-,-)$ & 58.4 & 26.8 & 1016 & 26.8 & -63.0 \\
5 & $(-,-,+,-)$ & 57.3 & 26.1 & 1219 & 31.2 & -89.8 \\
6 & $(+,-,+,-)$ & 56.6 & 26.8 & 1272 & 31.2 & -77.5 \\
7 & $(-,+,+,-)$ & 59.4 & 27.7 & 1258 & 29.1 & -85.6 \\
8 & $(+,+,+,-)$ & 56.0 & 26.9 & 1080 & 30.4 & -91.1 \\
9 & $(-,-,-,+)$ & 54.7 & 15.5 & 1018 & 36.5 & -62.6 \\
10 & $(+,-,-,+)$ & 56.3 & 16.5 & 1052 & 35.3 & -57.1 \\
11 & $(-,+,-,+)$ & 57.1 & 17.7 & 1148 & 36.1 & -61.2 \\
12 & $(+,+,-,+)$ & 56.7 & 18.1 & 1102 & 35.6 & -59.8 \\
13 & $(-,-,+,+)$ & 53.5 & 14.9 & 1060 & 37.7 & -59.8 \\
14 & $(+,-,+,+)$ & 53.7 & 15.6 & 991 & 37.5 & -63.9 \\
15 & $(-,+,+,+)$ & 56.0 & 16.8 & 1124 & 36.3 & -82.9 \\
16 & $(+,+,+,+)$ & 53.0 & 16.5 & 1023 & 37.1 & -78.8 \\
\hline
\end{tabular}

Effects of pulping variables on retention

Pulp chemical composition data and screening yield were combined to obtain the component retention (Table 4). 
The pulping process reduced approximately $83-96 \%$ of the original lignin present in wood, $40-56 \%$ of xylose and $7-15 \%$ of cellulose. Other minor hemicellulosic components were completely removed during pulping, and uronic acids were considered as the sum of hexenuronic and 4-O-methylglucuronic acids and expressed as $\mathrm{mol} /$ $100 \mathrm{~mol}$ of xylose. Uronic acids and xylose were used to calculate the xylan content ${ }^{22}$ in pulp samples and a complete removal of acetyl groups during pulping was assumed. ${ }^{28}$ The sums of cellulose, xylan and lignin were 99.1-.99.7\%. The residual parts of $0.3-0.9 \%$ could be attributed to extractives (ca $0.1 \%$ ), ash (ca $0.1 \%$ ), losses during acid hydrolysis and other variations of analytical methods. In this condition it was evident that differences in chemical composition observed in Table 4 were caused by a different combination of pulping parameters using the factorial design and not consequences of variations in analytical methods used.

Table 4. Pulp chemical composition and retention of carbohydrates and lignin obtained in 16 laboratory experiments according to a complete factorial design. Cellulose (CEL), xylan (XYL), and total lignin (TL) as \% of pulp dry weight. Uronic acids (UA) as mol/100 mol xylose. The cellulose/hemicelluose ratio $(\mathrm{CHr})$ was also calculated. The degree of polymerization (DP) of cellulose was estimated considering the XYL and CEL contents in each pulp. ${ }^{24}$ Retention (RCEL, R-XYL, and R-TL) presented as \% from original wood, dry weight

\begin{tabular}{|c|c|c|c|c|c|c|c|c|c|}
\hline Pulp & CEL & XYL & UA & TL & $\mathrm{CHr}$ & DP & RCEI & XYL & RTL \\
\hline 1 & 78.4 & 17.0 & 14.2 & 4.0 & 4.62 & 6898 & 44.5 & 9.6 & 2.3 \\
\hline 2 & 76.2 & 16.2 & 14.8 & 7.0 & 4.69 & 5898 & 46.6 & 9.9 & 4.3 \\
\hline 3 & 77.1 & 16.6 & 15.4 & 6.1 & 4.64 & 5588 & 46.8 & 10.1 & 3.7 \\
\hline 4 & 77.1 & 16.5 & 16.6 & 5.8 & 4.67 & 5217 & 45.0 & 9.6 & 3.4 \\
\hline 5 & 78.8 & 16.9 & 12.4 & 3.8 & 5.03 & 6427 & 45.2 & 9 & 2.2 \\
\hline 6 & 79.0 & 15.7 & 14.7 & 4.9 & 4.93 & 6656 & 44.7 & 8 & 2.8 \\
\hline 7 & 78.5 & 15.9 & 17.3 & 4.8 & 5.18 & 64 & 46.6 & & 2.9 \\
\hline 8 & 79.9 & 15.4 & 14.1 & 4.2 & 5.53 & 5382 & 44.7 & 8 & 2.4 \\
\hline & 82.2 & 14.9 & 11.8 & 2.5 & 5.53 & 5032 & 45.0 & 8 & 1.4 \\
\hline 10 & 80.8 & 14.6 & 11.7 & 3.7 & 5.77 & 5184 & 45.5 & 8.2 & 2.1 \\
\hline 11 & 82.9 & 14.4 & 10.2 & 2.1 & 6.14 & 5645 & 47.3 & 8.2 & 1.2 \\
\hline 12 & 82.6 & 13.5 & 11.4 & 3.4 & 6.09 & 5313 & 46.8 & 7.6 & 1.9 \\
\hline 13 & 83.3 & 13.7 & 10.5 & 2.1 & 6.08 & 5023 & 44.6 & 7.3 & 1.1 \\
\hline 14 & 82.5 & 13.6 & 12.0 & 3.3 & 5.87 & 4710 & 44.3 & 7.3 & 1.8 \\
\hline 15 & 82.5 & 14.0 & 11.5 & 3.2 & 3.31 & 5407 & 46.2 & 7.8 & 1.8 \\
\hline 16 & 82.7 & 13.1 & 14.0 & 3.5 & 6.31 & 4890 & 43.8 & 6.9 & 1.9 \\
\hline
\end{tabular}

\section{Xylan retention}

Figure 1 shows the normal plot of effects obtained for xylan retention. The pulping variable that affected retention was identified in this plot by the point lying outside the expected normal. AA affected xylan retention in a significant way. However, heating rate $(\mathrm{V})$, temperature (T), sulfidity (S) and their interactions did not affect the retention at the levels investigated here. Higher levels of
AA decreased the xylan retention due to alkaline hydrolysis or physical dissolution at high temperatures. ${ }^{29}$

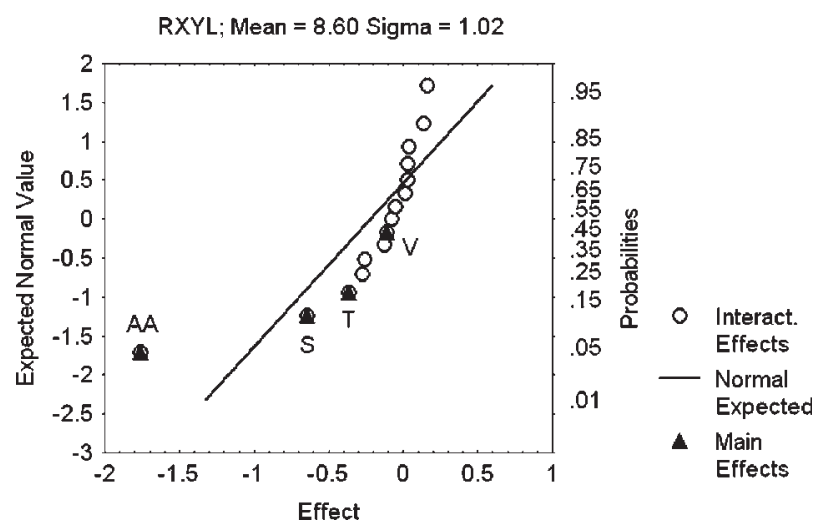

Figure 1. Normal probability plot of the effects for xylan retention. AA was the variable out of the expected normal, thus with significant effects on xylan retention. Similar results were obtained by ANOVA.

The content of uronic acid side groups in xylan was also affected by AA (Figure 2). They were probably removed by dissolution of xylan fragments, alkaline hydrolysis of uronosidic bonds between the acid units and the backbone or uronic acid decomposition via decarboxylation. ${ }^{30}$ Alkali was consumed to convert part of the 4-O-methylglucuronic acids to hexenuronic acids but this fraction was not considered in this effect since one could assume that most hexenuronic units remain in the pulp after this conversion.

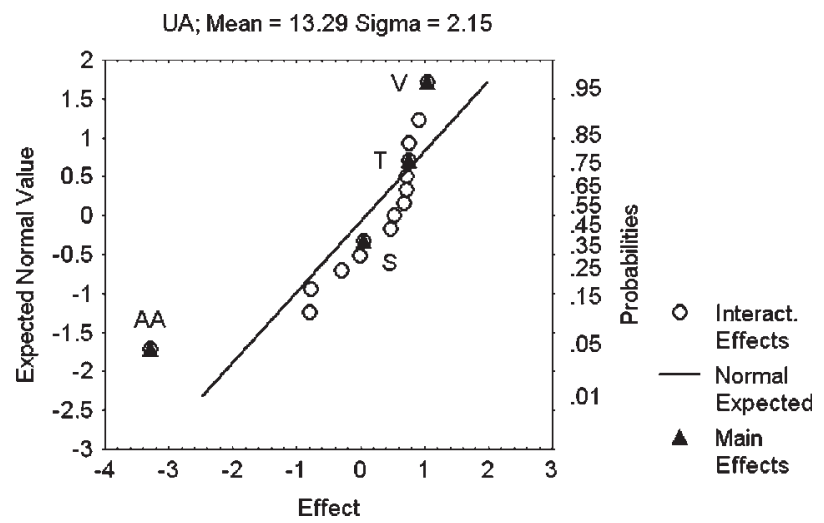

Figure 2. Normal probability plot of the effects for uronic acid content in xylan.

\section{Lignin retention}

The total lignin in pulp was determined as the sum of acid insoluble and soluble lignin. Lignin retention was affected by AA (Figure 3). S that is usually reported to be relevant for lignin removal did not affect the retention at 
the levels investigated here, probably because the levels in the experiments were relatively close. The use of higher AA levels also implies addition of higher amounts of sulfur species in the cooking medium, contributing to delignification due to cleavage of $\beta$-aryl ether bonds by $\mathrm{HS}^{-}$. The $\mathrm{OH}^{-}$species undergo the formation of a phenolate ion that is a precursor for the cleavage of $\alpha$-aryl ether bonds and for the insertion of $\mathrm{HS}^{-}$in phenylpropane units. This condition is essential to have the $\beta$-aryl ether cleavage in lignin macromolecules. ${ }^{4}$ The interactive action of these species seemed to be the reason for the kraft pulping versatility.

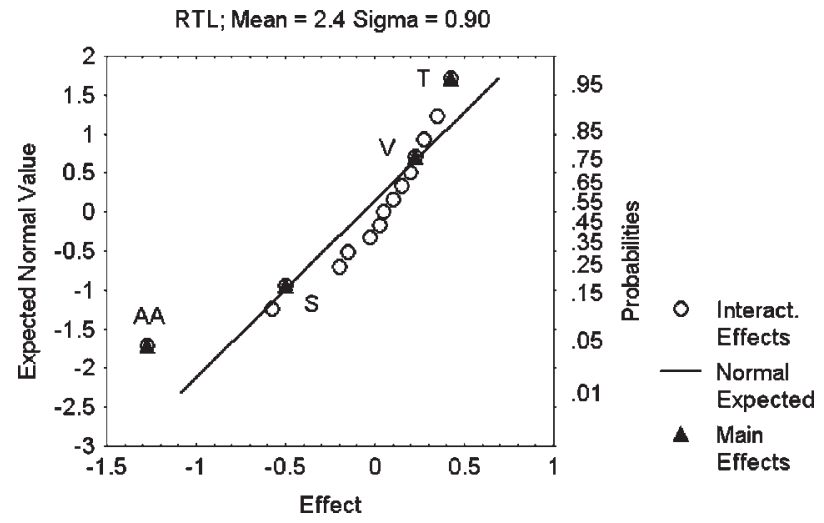

Figure 3. Normal probability plot of the effects for total lignin retention.

\section{Cellulose retention}

The retention of cellulose was not affected by the investigated variables (Figure 4), despite the slight reduction relative to the original amount present in wood. This reduction might have occurred due to exposure of cellulose microfibrils during chip preparation or due to polymer chain peeling before the stabilizing stop reaction. It was possible that lignin and hemicelluloses removal protected the cellulose from degradation since these components are located in fiber regions more accessible to the pulping liquor, i.e. covering the cellulose microfibril surfaces. ${ }^{31}$ The higher degree of polymerization of cellulose in comparison with xylan also favored its retention since this cellulose macromolecule can even be retained after some degradation.

The degree of polymerization (DP) of cellulose was included in the factorial design in order to determine if macromolecular degradation of cellulose was affected by pulping variables (Figure 5). The AA affected the DP in a way that higher macromolecular degradation was observed when higher AA levels were used. This might have been due to effects of alkali concentration on cellulose

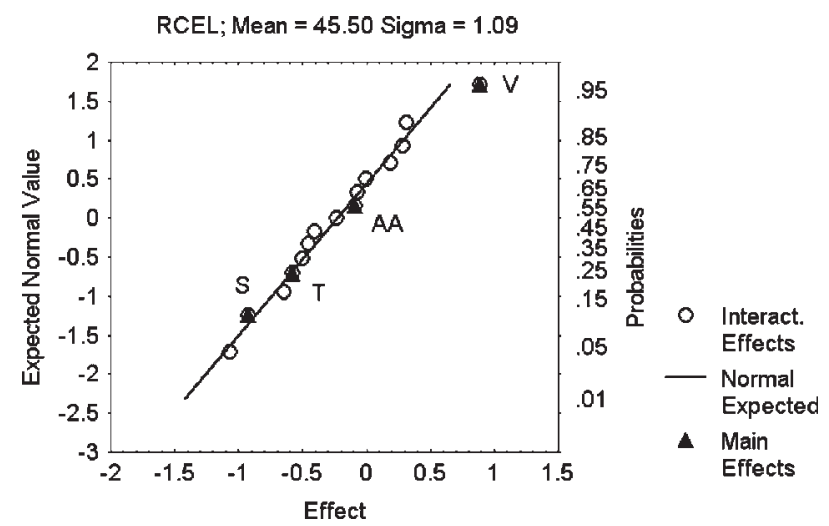

Figure 4. Normal probability plot of the effects for cellulose retention. Pulping variables did not affect cellulose retention.

degradation via stepwise peeling of monomer units or chain scission by alkaline hydrolysis. However, cellulose removal during macromolecular degradation was apparently limited by the short pulping time and accessibility of cellulose fibrils.

It is important to point out that the results observed here are very dependent on the wood structure which could address penetration and diffusion of pulping liquor in short periods. The porous structure of eucalyptus wood allows rapid penetration of pulping liquor and heat transfer. ${ }^{32}$ This characteristic can significantly reduce the pulping time. The same results cannot be expected for wood that shows reduced liquor penetrability, for example caused by tyloses.

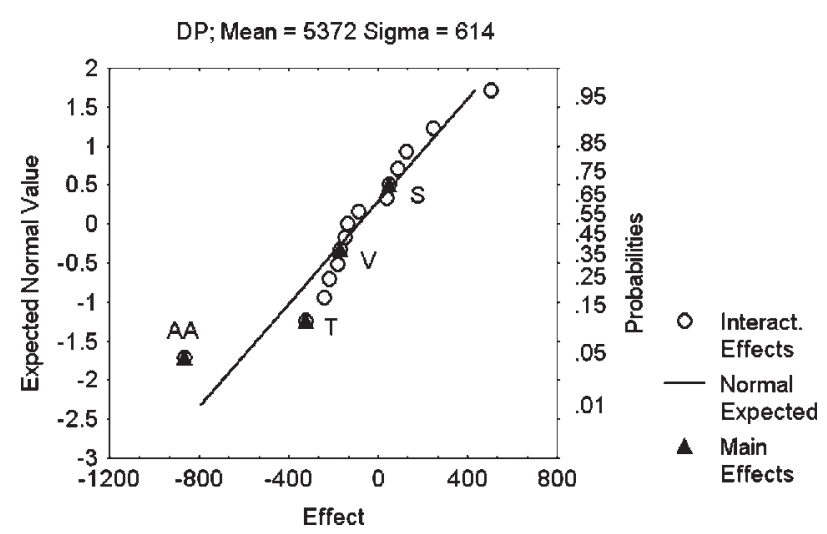

Figure 5. Normal probability plot of the effects for degree of polymerization of cellulose. Active alkali affected the macromolecular degradation of cellulose.

Overall, of the pulping variables investigated here, AA extensively affected the retention of pulp components. The pulps obtained in retention experiments (Table 3) can be grouped into two different kappa number ranges according to the AA level used, i.e. kappa 26.1-31.9 (pulps 1-8) and kappa 15.5-18.1 (pulp 9-16) for high and low AA 
levels, respectively. Currently, the industry uses the latter kappa range for production of eucalyptus pulps in many countries, including Brazil and Portugal. On the other hand, advantages of producing eucalyptus pulps with kappa 27 have been reported, particularly regarding the improvement in delignification selectivity during oxidative stages. ${ }^{33}$ In the next section, the influence of component retention using high and low AA levels on physicochemical and mechanical properties of the pulps was investigated. One may argue that comparing pulps with such differences in kappa number is not appropriate because the influence of lignin can be striking. As observed earlier, ${ }^{28,34}$ however, the lignin content of pulps obtained here in the range of 2-7\% (Table 4) make them comparable.

\section{Effects of component retention on physicochemical properties}

PCA was used to study the relationship between pulp chemical composition, kappa number, ISO brightness, intrinsic viscosity and zeta potential. Two PCs, explaining $72.2 \%$ and $14.9 \%$ of the variance, were selected. A score plot containing PC1 and PC2 was plotted and a clear separation between samples obtained with low and high AA levels was extracted by PC1 (Figure 6). The loads plot showed that kappa number (KP), xylan (XYL), uronic acid (UA), total lignin (TL), cellulose (CEL), and ISO brightness (BR) were the variables most affected by the different AA levels in pulping because of their significant contribution to PC1 (Figure 7). Intrinsic viscosity (IV) and zeta potential

Table 5. Fiber length, sheet apparent density, and mechanical properties of laboratory pulp samples obtained in 16 experiments. Fiber length (FL) as $\mu \mathrm{m}$; apparent density (AD) as $\mathrm{gcm}^{-3}$. Tear index (TrID) as $\mathrm{mNm}^{2} \mathrm{~g}^{-1}$; tensile index (TsID) as $\mathrm{Nmkg}^{-1}$; burst index (BuID) as $\mathrm{kPam}^{2} \mathrm{~g}^{-1}$; bending index (BeID) as $\mathrm{mNm}^{2} \mathrm{~g}^{-1}$; stretch (ST) as $\%$ and elastic modulus (EM) as $\mathrm{MNmkg}^{-1}$

\begin{tabular}{lcccccccc}
\hline Pulp & AD & FL & TrID & TsID & BuID & BeID & ST & EM \\
\hline 1 & 0.52 & 940 & 4.7 & 32.1 & 1.10 & 3.17 & 0.61 & 7.6 \\
2 & 0.52 & 990 & 7.1 & 28.2 & 1.27 & 2.32 & 0.57 & 6.2 \\
3 & 0.50 & 980 & 6.0 & 26.4 & 1.05 & 2.94 & 0.59 & 6.4 \\
4 & 0.51 & 990 & 6.8 & 29.8 & 1.04 & 2.38 & 0.56 & 7.4 \\
5 & 0.51 & 930 & 5.7 & 34.7 & 1.19 & 3.35 & 0.66 & 8.1 \\
6 & 0.51 & 970 & 5.6 & 35.7 & 1.26 & 2.99 & 0.58 & 8.4 \\
7 & 0.50 & 980 & 7.0 & 33.3 & 1.23 & 3.29 & 0.66 & 7.4 \\
8 & 0.52 & 980 & 5.8 & 31.9 & 1.15 & 2.99 & 0.64 & 7.5 \\
9 & 0.46 & 870 & 3.8 & 20.9 & 0.65 & 2.15 & 0.58 & 5.1 \\
10 & 0.47 & 940 & 4.6 & 25.3 & 0.88 & 3.28 & 0.57 & 6.1 \\
11 & 0.47 & 920 & 3.8 & 23.5 & 0.81 & 3.12 & 0.57 & 5.9 \\
12 & 0.47 & 940 & 5.0 & 27.7 & 0.83 & 3.21 & 0.63 & 6.6 \\
13 & 0.47 & 870 & 2.7 & 20.7 & 0.65 & 2.35 & 0.59 & 5.2 \\
14 & 0.48 & 920 & 4.1 & 26.7 & 0.85 & 3.33 & 0.53 & 7.0 \\
15 & 0.47 & 910 & 4.1 & 21.7 & 0.75 & 2.09 & 0.55 & 5.5 \\
16 & 0.49 & 920 & 5.0 & 27.1 & 0.77 & 2.37 & 0.52 & 7.2 \\
\hline
\end{tabular}

(ZP) contributed mostly to PC2. The use of a low AA level in pulping tended to increase the contents of XYL, TL and UA. As a consequence, KP and BR were the main physicochemical properties affected. The relationship between the variables assessed by the loads plot showed that XYL was positively related to KP and negatively related to BR and CEL. Influences of UA and TL on KP were also observed by the $\mathrm{PC} 1$, but considering both $\mathrm{PCs}$ the influence of XYL was dominant. Effect of XYL on KP was observed earlier and attributed to hexenuronic acid side groups formed in pulping. ${ }^{35}$ In fact, xylan could also form lignincarbohydrate complexes (LCC) ${ }^{36,37}$ or other chromophore

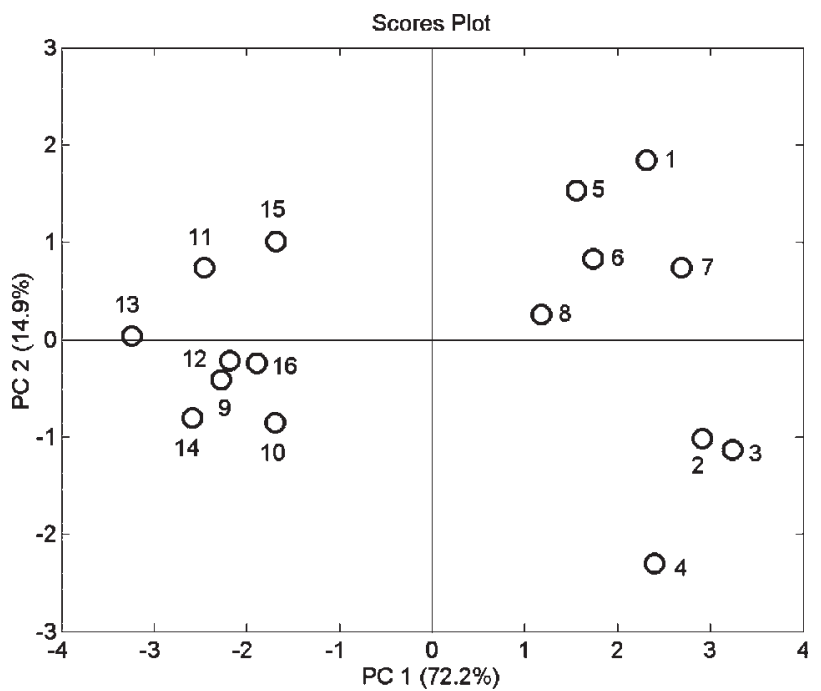

Figure 6. Scores plot of PCA analysis using pulp chemical composition and physicochemical properties. Samples obtained with low (numbers 1-8) and high (numbers 9-16) AA levels are clearly separated by the PC1.

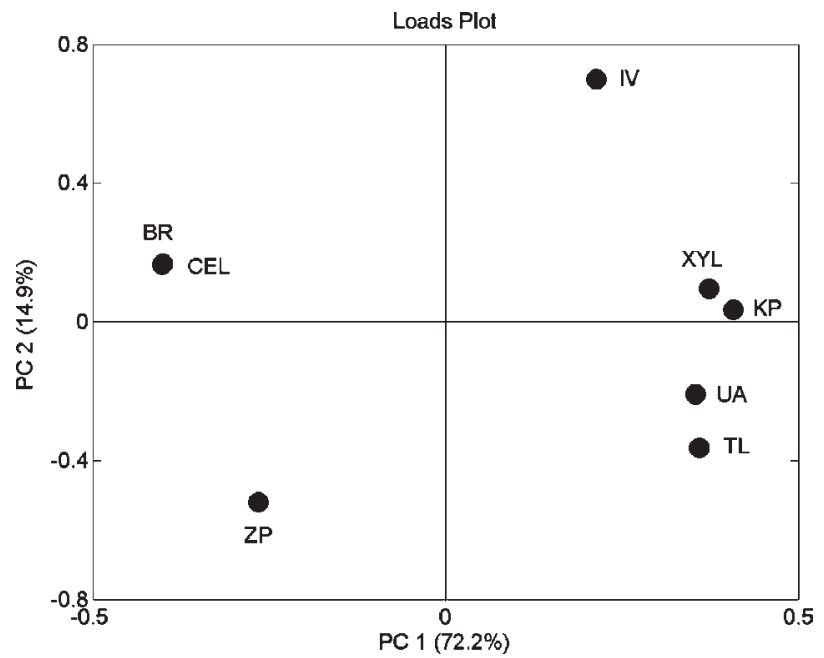

Figure 7. Loads plot of PCA analysis for pulp chemical composition and physicochemical properties. Xylan (XYL) was related to kappa number (KP), ISO brightness (BR) and cellulose (CEL). Uronic acids (UA) and total lignin (TL) were related to zeta potential (ZP). Intrinsic viscosity (IV) was not related to the chemical composition. 
group by uronic acid decomposition ${ }^{30}$ and thus have additional contributors to increase KP and lower BR.

The loads plot also showed that ZP was negatively related with $\mathrm{UA}$ and $\mathrm{TL}$, indicating that lower $\mathrm{ZP}$, i.e. higher surface charge, was observed at low AA levels in pulping. This could be explained by the removal of UA units from xylan and carboxyl groups from lignin when a high AA level was used. Additionally, it suggested that the macromolecular degradation of cellulose did not generate enough metasaccharinic acid groups at the fiber surfaces in order to compensate the ones removed from lignin and UA. ${ }^{38}$

\section{Effects of component retention on mechanical properties}

PCA was employed to evaluate the relationship between chemical composition, fiber length (FL), apparent sheet density (AD) and mechanical properties. Tear (TrID), tensile (TsID), burst (BuID), and bending (BeID) indices as well as elastic modulus (EM) and stretch (ST) were the mechanical properties investigated. Chemical composition, cellulose/hemicellulose ratio $(\mathrm{CHr})$ and $\mathrm{DP}$ were also included. Two PCs were found to describe $65.7 \%$ and $13.9 \%$ of the variation, respectively. The scores plot showed that the PC1 again separated samples produced with low and high AA levels (Figure 8). The loads plot showed that using a low level of AA in pulping favored all strength properties, FL and DP, but reduced the $\mathrm{CHr}$ due to higher xylan retention (Figure 9). Pulp hand sheets with lower $\mathrm{AD}$ were obtained when a high $\mathrm{AA}$ level was used, indicating a reduction in fiber-to-fiber bonding in the sheet network.

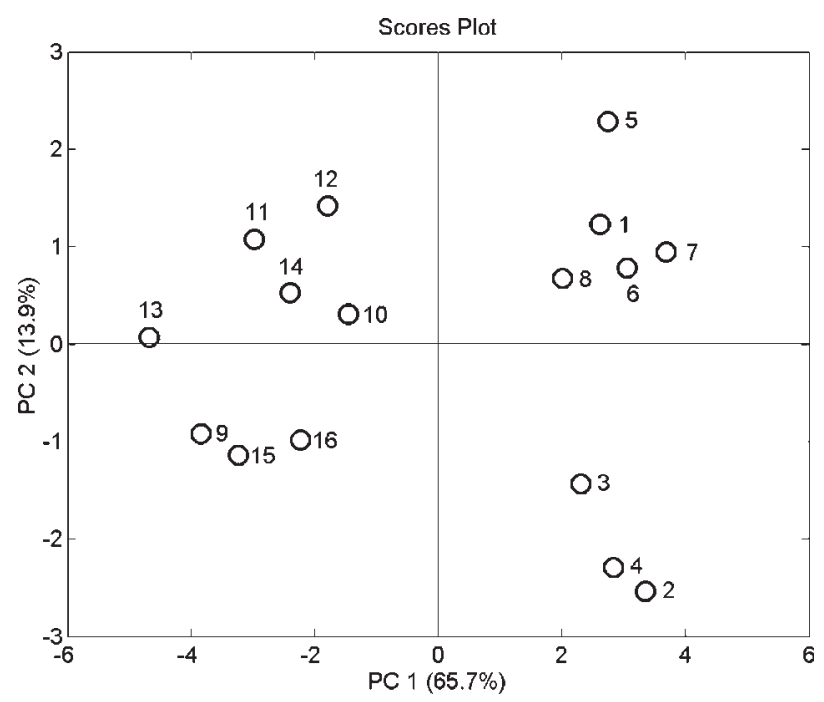

Figure 8. Scores plot of PCA analysis using pulp chemical composition, fiber length, sheet apparent density and mechanical properties. Samples obtained with low (numbers 1-8) and high (numbers 9-16) AA levels are clearly separated by the PC1.
When PC1 and PC2 were considered the loads plot showed that EM was positively related with DP and TsID. BuID was negatively related with $\mathrm{CHr}$ and, according to its contribution to $\mathrm{PC} 1$, was the mechanical property most affected by using a high AA level in pulping. BeID and ST did not appear to be related to EM or any chemical composition data. The XYL content was positively related with $\mathrm{AD}$, and thus had a more extensive influence in fiberto-fiber bonding than the other components. Another indication of this plot was that TrID was not related to EM or CEL, but instead was positively related to FL and UA. Effect of FL on TrID was observed earlier ${ }^{19,39}$ as well as the lack of correlation between FL and TsID. ${ }^{40,41}$ In addition to FL, a clear influence of UA on TrID was observed (Figure 10). This finding suggested that the characteristics of XYL preserved in pulp were more relevant to TrID than the XYL content. Usually, XYL content has been reported to be detrimental to TrID of softwood pulps while it has no effect or very little contribution to birch pulp..$^{34,42,43}$ In fact, the modifications in XYL structure during pulping should be considered. In conventional pulping, XYL is dissolved and after partial degradation and removal of its UA side groups is sorbed onto fiber surfaces. This relocated xylan can account for $10 \%$ and $50 \%$ of xylan in birch $^{44}$ and pine ${ }^{45}$ pulps, respectively. More recently, it was shown that XYL sorption requires long deposition times and extensive removal of UA side groups. ${ }^{46}$ Thus, it seemed that the short pulping cycle used here combined with the low AA level favored the preservation of UA in XYL in its original location,

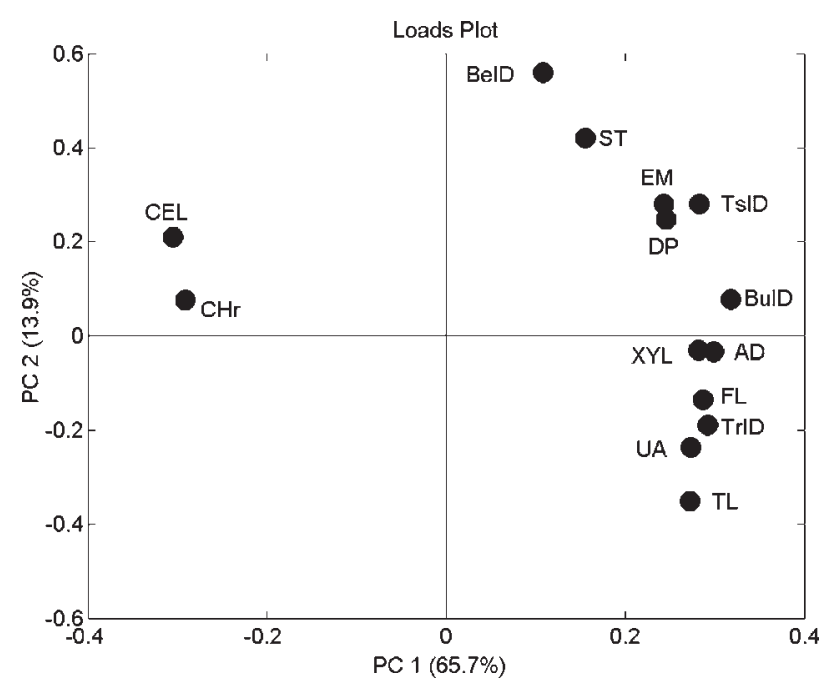

Figure 9. Loads plot of PCA analysis for pulp chemical composition, fiber length and mechanical properties. Xylan (XYL) was related with apparent sheet density (AD). Uronic acids (UA) and fiber length (FL) were positively related to tear index (TrID). Elastic modulus (EM) was positively related to tensile index (TsID) and degree of polymerization of cellulose (DP). Bending index (BeID) and stretch (ST) were not related to EM or any chemical composition data. 


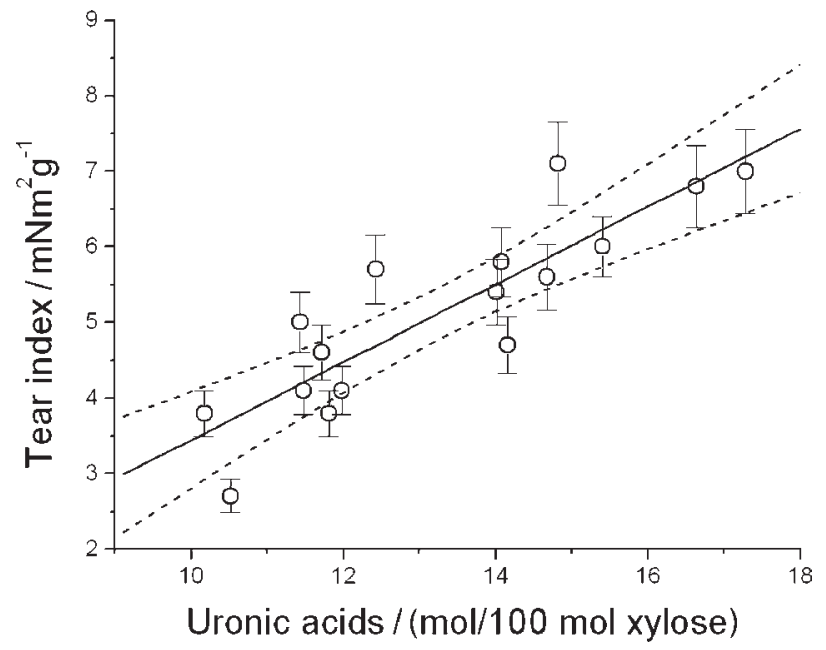

Figure 10. Tear index (TrID) versus uronic acids (UA) in xylan. A similar tendency was observed for UA and TrID confirming the results obtained by PCA. A linear fit with a $95 \%$ confidence interval (dashed line) is presented.

i.e on the surface of cellulose fibrils. The presence of these carboxyl groups could induce local swelling, contributing to increase the fiber wall swelling and flexibility. In this condition, it is conceivable that a synergy between swelling and FL increased the fiber-to-fiber contact area in the sheet network. This improvement in the bonded area affected the work necessary to pull out the fibers from the network and consequently increased TrID of unbeaten eucalyptus pulp.

In terms of industrial application, a combination of short time, thin chips and low AA level in pulping can bring benefits of improved yield and all mechanical properties of unbleached pulp. Improvements in TrID and BuID are particularly attractive for packaging papers. Additional profit regarding alkali production costs in the recovery system can also be achieved. Obviously, the negative impacts on BR are expected to require a high dosage of chemicals in conventional bleaching sequences. Therefore, more selective bleaching strategies for this type of pulp need to be further investigated.

\section{Conclusion}

Active alkali is the pulping variable which most affects the retention of xylan, uronic acids, lignin and the macromolecular degradation of cellulose in fast kraft pulping of eucalyptus. Cellulose retention is not affected by different cooking variables and appears to be protected by preferential removal of hemicelluloses and lignin in combination with limited macromolecular degradation in short pulping cycles. The use of low active alkali levels in pulping improves all mechanical properties of the pulp, but reduces ISO brightness and increases kappa number and surface charge. Xylan affects ISO brightness and kappa number while uronic acids and total lignin are related to the surface charge. The degree of polymerization of cellulose is related to elastic modulus of the sheet and tensile index, but appears to have no influence on tear index. Xylan affects the apparent sheet density, probably because it improves fiber-to-fiber bonding. The tear index is affected by the fiber length and content of uronic acid side groups in xylan, which tend to be preserved when a low AA level, thin wood chips and short pulping cycles are combined. The characteristics, rather the content of xylan, are suggested to be relevant to tear index.

\section{Acknowledgements}

Support from Suzano Papel e Celulose, Åbo Akademi Process Chemistry Centre and linguistic revision by Donald MacNeil are acknowledged. Part of this work was presented at the International Symposium on Wood and Pulping Chemistry, Nice, France, June 2001.

\section{References}

1. Gullichsen, J. In Chemical Pulping; Gullichsen, J., Fogelholm, C-J., eds.; Fapet Oy: Helsinki, Finland, 2000; Vol. 6A, ch. 2.

2. Hartler, N.; Nord. Pulp Pap. Res. J. 1997, 12, 115.

3. Gellerstedt, G. In Wood and Cellulosic Chemistry, 2nd ed.; Hon, D. N.-S., Shiraishi, N., eds.; Marcel Dekker, Inc: New York, 2001; ch. 25.

4. Gierer, J.; Holzforschung 1982, 36, 43.

5. Berggren, R., Molin, U., Berthold, F., Lennholm, H., Lindström, M.; Carbohyd. Polym. 2003, 51, 255.

6. Knill, C., Kennedy, J. F.; Carbohyd. Polym. 2003, 51, 281.

7. Sjöström, E.; Nord. Pulp Pap. Res. J. 1989, 4, 90.

8. Schönberg, C., Oksanen, T., Suurnäkki, A., Kettunen, H., Buchert, J.; Holzforschung 2001, 55, 639.

9. Genco, J., Busayasakul, N., Medhora, H. K., Robbins, W.; Tappi J. 1990, 73, 223.

10. Scott, R.; J. Wood Chem. Technol. 1984, 4, 199.

11. Spiegelberg, H. L.; Tappi 1966, 49, 388.

12. Centola, G., Borruso, D.; Tappi 1967, 50, 344.

13. McDonough, T. J.; Proceedings of the Breaking the Pulp Yield Barrier Symposium, Atlanta, USA, 1998.

14. Gomide, J. L., Fantuzzi Neto, H., Colodette, J. L.; Proceedings of the 5th Brazilian Symposium on the Chemistry of Lignins and other Wood Components, Curitiba, Brazil, 1997.

15. Carvalho, M. G., Ferreira, P. J., Figueiredo, M. M.; Cellulose 2000, 7, 359.

16. Daniel, A. I. D., Evtuguin, D. V., Silvestre, A. J. D., Pascoal Neto, C.; Proceedings of the 6th European Workshop on Lignocellulosics and Pulp, Bordeaux, France, 2000. 
17. Johnston, R. E., Li, M., Waschl, R.; Appita J. 1997, 50, 307.

18. Ona, T., Sonoda, T., Ito, K., Shibata, M., Tamai, Y., Kojima, Y., Ohshima, J., Yokota, S. Yoshizawa, N.; Wood Sci. Technol. 2001, 35, 229.

19. Wimmer, R., Downes, G. M, Evans, R., Rasmussen, G., French, J.; Holzforschung 2002, 56, 244.

20. Fardim, P. and Durán, N.; Proceedings of the 6th Brazilian Symposium on the Chemistry of Lignins and other Wood Components, Guaratinguetá, Brazil, 1999.

21. Scott, R.W.; Anal. Chem. 1979, 51, 936.

22. Janson, J.; Рар. Рии 1970, 5, 323.

23. Effland, M.; Tappi 1977, 60, 143.

24. Perez, D. ; Van Heiningen, A.; Proceedings of the $7^{\text {th }}$ European Workshop on Lignocellulosics and Pulp, Turku/Åbo, Finland, 2002.

25. Vaaler, D., Berthold, F., Moe, S.; Proceedings of the 12nd International Symposium on Wood and Pulping Chemistry, Madison, USA, 2003.

26. Barros Neto, B.; Scarminio, I. S.; Bruns, R. E.; Planejamento e Otimizacão de Experimentos, Editora da UNICAMP: Campinas, 2001.

27. Wold, S.; Esbensen, K.; Geladi, P.; Chemometr. Intell. Lab. Syst. 1987, 2, 37.

28. Rydholm, S.A.; Pulping Processes, Interscience Publishers: New York, 1965.

29. Hirai, H.; Kondo, R.; Sakai, K.; Mokuzai Gakkaishi 1997, 43, 247.

30. Casebier, R.; Hamilton, J.; Tappi 1967, 50, 441.

31. Harada, H.; Côté, W. A.; Biosynthesis and Biodegradation of Wood Components, Academic Press: New York, 1985.
32. Kramer, J.; Proceedings of the 31th Pulp and Paper Annual Meeting, São Paulo, Brazil, 1998.

33. Colodette, J.; Gomide, J.; Sales D.; Brito, A.; Oliveira Filho, A.; Papel 1995, 56, 40.

34. Annergren, G.; Rydholm, S.; Vardheim, S.; Svensk Paperstidn. 1966, 66, 197.

35. Li, J.; Gellerstedt, G.; Nord. Pulp Pap. Res. J. 1998, 13, 147.

36. Iversen, T.; Wännström, S.; Holzforschung 1986, 40, 19.

37. Hortling, B.; Turunen, E.; Sundquist, J.; Nord. Pulp Pap. Res. J. 1992, 3, 144.

38. Fardim, P.; Holmbom, B.; Proceedings of the 12nd International Symposium on Wood and Pulping Chemistry, Madison, USA, 2003.

39. Clark, J. d'A.; Paper Trade J. 1942, 115, 36.

40. Marton, R.; Alexander, S. D.; Brown, A. F.; Sherman, C. W.; Tappi 1965, 48, 395

41. Takahashi, H.; Suzuki, H.; Endoh, K.; Tappi 1979, 62, 85.

42. Petterson, S.; Rydholm, S.; Svensk Paperstidn. 1961, 64, 4.

43. Sjöberg, J.; Ph.D. Thesis, Royal Institute of Technology, Sweden, 2002.

44. Axelsson, S.; Croon, I.; Enström, B.; Svensk Papperstidn. 1962, 65, 693.

45. Yllner, S.; Östberg, K.; Stockman, L.; Svensk Papperstidn. 1957, 60, 795.

46. Linder, Å.; Ph.D. Thesis, Chalmers University of Technology, Sweden, 2003.

Received: September 29, 2003

Published on the web: June 29, 2004

FAPESP helped in meeting the publication costs of this article. 